\title{
A Simple but Accurate Formula for the Saturation Vapor Pressure Over Liquid Water
}

\author{
S. TABATA \\ Marine Sciences Directorate, Environment Canada, Victoria, B. C.
}

7 July 1973 and 4 September 1973

Oceanographers and hydrometeorologists make wide use of saturation vapor pressure to estimate evaporation over large bodies of water. In the past, the values of saturation vapor pressure were frequently obtained from those tabulated in reference books [e.g., the Smithsonian Meteorological Tables (List, 1949)], and in a variety of handbooks (e.g., Handbook of Meteorology (Berry $e t a l ., 1945)]$. These values can also be obtained efficiently by utilizing a suitable table look-up routine in a computer program. When large number of values are required it is more common nowadays to compute each value of saturation vapor pressure by use of appropriate formula. This second technique has the advantage over the first in that the values can be obtained for any increment of temperature and is therefore more flexible. If the volume of computations is enormous, such as is the case with the numerical study of the general atmospheric circulation including the hydrological cycle, then the demand for computation efficiency has to be met as well. A simple but accurate formula would be useful in such a case.

In order to improve this efficiency, and at the same time retain the desirable accuracy of the estimates of saturation vapor pressure over water, a simple quadratic formula relating the logarithm of the vapor pressure in terms of the temperature is proposed which can reproduce values within $0.2 \%$ of the accepted saturation values.

The values of saturation vapor pressure within the temperature range -50 to less than $100 \mathrm{C}$, tabulated in the Smithsonian Meteorological Tables, is based on the Goff-Gratch formulation (Goff and Gratch, 1946) and are obtained by the use of the formula:

$$
\begin{aligned}
\log _{10} e= & -7.90298\left(\frac{\theta_{3}}{\theta}-1\right)+5.02808 \log _{10}\left(\frac{\theta_{s}}{\theta}\right) \\
& -1.3816 \times 10^{-7}\left[10^{11.344\left(1-\theta / \theta_{3}\right)}-1\right] \\
& +8.1328 \times 10^{-3}\left[10^{-3.4914 \theta\left(\theta_{z} /(\theta-1)\right.}-1\right]
\end{aligned}
$$

where $e$ is the saturation vapor pressure over a plane surface of pure ordinary liquid water (atmosphere), $\theta_{8}$ the steam-point temperature $(373.16 \mathrm{~K})$, and $\theta$ the absolute (thermodynamic) temperature $\left({ }^{\circ} \mathrm{K}\right)\left[\theta\left({ }^{\circ} \mathrm{K}\right)\right.$ $=T+273.15$, where $T$ is the temperature in degrees
Celsius]. This formula is based on the integration of the Clausius-Clapeyron equation considering the deviations from a perfect gas and utilizing empirical results. This formula is recommended by the International Joint Committee on Psychrometric Data (Goff, 1949).

Berry et al. (1945) have adopted a simpler formula:

$$
\log _{e}\left(\frac{e}{6.105}\right)=25.22\left(\frac{\theta-273}{\theta}\right)-5.31 \log _{e}\left(\frac{\theta}{273}\right)
$$

which was originally derived by Kiefer (1941). The vapor pressure $e$ is in millibars.

More recently, Langlois (1967) has proposed an approximate formula based on that of Berry et al. It is written

$$
e \approx \frac{\theta^{2}-488.56 \theta+60009.3}{0.0361622 \theta^{2}-24.209 \theta+4104.45}
$$

where $e$ is in millibars.

In the present study two empirical formulas are suggested, utilizing the values of saturation vapor pressure listed in the Smithsonian Meleorological Tables.

These are

$\log _{10} e=9.28603523-2.32237885\left(\frac{10^{3}}{\theta}\right)$

and

$$
\begin{array}{r}
\log _{10} e=8.42926609-1.82717843\left(\frac{10^{3}}{\theta}\right) \\
-0.071208271\left(\frac{10^{3}}{\theta}\right)^{2},
\end{array}
$$

where $e$ is in millibars.

The values of saturation vapor pressure obtained by the use of the two formulas are shown in Table 1 along with those obtained from the Smithsonian Meteorological Tables and by the use of the formulas proposed by Berry $e t a l$. and by Langlois.

A comparison of the calculated and accepted (Smithsonian Meteorological Tables) values indicates that despite its simplicity the quadratic formula (5) yields saturation values that are very close to the accepted 
Table 1. Saturation vapor pressure $(\mathrm{mb})$ over water.

\begin{tabular}{|c|c|c|c|c|c|c|c|c|c|}
\hline \multirow{2}{*}{$\begin{array}{c}\begin{array}{c}\text { Temperature } \\
\left({ }^{\circ} \mathrm{C}\right)\end{array} \\
-15.0 \\
-10.0 \\
-5.0\end{array}$} & \multirow{2}{*}{$\begin{array}{l}\text { (a) } \\
1.9118 \\
2.8627 \\
4.2148\end{array}$} & \multicolumn{3}{|c|}{$\begin{array}{l}\text { Saturation vapor pressure } \\
\begin{array}{lll}\text { (b) } & \text { (c) } & \text { (d) }\end{array}\end{array}$} & \multirow{2}{*}{$\begin{array}{l}\text { (e) } \\
1.9976 \\
2.9102 \\
4.2546\end{array}$} & \multirow{2}{*}{$\begin{array}{c}\text { (b) } \\
+1.97 \\
+0.92 \\
+0.12\end{array}$} & \multicolumn{2}{|c|}{$\begin{array}{l}\text { Percent error (f) } \\
\begin{array}{ll}\text { (c) } & \text { (d) }\end{array}\end{array}$} & \multirow{2}{*}{$\begin{array}{c}\text { (e) } \\
+4.88 \\
+1.66 \\
+0.94\end{array}$} \\
\hline & & $\begin{array}{l}1.9489 \\
2.8889 \\
4.2198\end{array}$ & $\begin{array}{l}1.9176 \\
2.8673 \\
4.2163\end{array}$ & $\begin{array}{l}1.9044 \\
2.8541 \\
4.2078\end{array}$ & & & $\begin{array}{l}+0.30 \\
+0.16 \\
+0.04\end{array}$ & $\begin{array}{l}-0.44 \\
-0.30 \\
-0.17\end{array}$ & \\
\hline $\begin{array}{r}0.0 \\
5.0 \\
10.0 \\
15.0 \\
20.0 \\
25.0 \\
30.0 \\
35.0\end{array}$ & $\begin{array}{c}6.1078 \\
8.7192 \\
12.272 \\
17.044 \\
23.373 \\
31.671 \\
42.430 \\
56.236\end{array}$ & $\begin{array}{c}6.0789 \\
8.6429 \\
12.137 \\
16.843 \\
23.114 \\
31.386 \\
42.190 \\
56.171\end{array}$ & $\begin{array}{c}6.1036 \\
8.7063 \\
12.248 \\
17.005 \\
23.321 \\
31.610 \\
42.375 \\
56.215\end{array}$ & $\begin{array}{l}6.1050 \\
8.7245 \\
12.291 \\
17.083 \\
23.491 \\
31.778 \\
45.588 \\
56.454\end{array}$ & $\begin{array}{c}6.1628 \\
8.8061 \\
12.404 \\
17.236 \\
23.643 \\
32.027 \\
42.821 \\
56.412\end{array}$ & $\begin{array}{l}-0.47 \\
-0.88 \\
-1.00 \\
-1.17 \\
-1.11 \\
-0.90 \\
-0.56 \\
-0.12\end{array}$ & $\begin{array}{l}-0.07 \\
-0.15 \\
-0.20 \\
-0.23 \\
-0.22 \\
-0.19 \\
-0.13 \\
-0.04\end{array}$ & $\begin{array}{l}-0.05 \\
+0.06 \\
+0.15 \\
+0.23 \\
+0.29 \\
+0.34 \\
+0.37 \\
+0.39\end{array}$ & $\begin{array}{l}+0.90 \\
+1.00 \\
+1.08 \\
+1.13 \\
+1.16 \\
+1.12 \\
+0.92 \\
+0.31\end{array}$ \\
\hline $\begin{array}{l}40.0 \\
45.0 \\
50.0\end{array}$ & $\begin{array}{l}73.777 \\
95.855 \\
123.40\end{array}$ & $\begin{array}{l}74.105 \\
96.917 \\
125.70\end{array}$ & $\begin{array}{c}73.838 \\
96.079 \\
123.90\end{array}$ & $\begin{array}{l}74.062 \\
96.208 \\
123.81\end{array}$ & $\begin{array}{l}73.012 \\
92.437 \\
113.87\end{array}$ & $\begin{array}{l}+0.44 \\
+1.11 \\
+1.86\end{array}$ & $\begin{array}{l}+0.01 \\
+0.13 \\
+0.40\end{array}$ & $\begin{array}{l}+0.39 \\
+0.39 \\
+0.33\end{array}$ & $\begin{array}{l}-1.04 \\
-3.56 \\
-7.72\end{array}$ \\
\hline \multicolumn{4}{|c|}{ Mean percentage error (g) } & \multicolumn{2}{|c|}{$\begin{array}{c}(-15 \text { to } 50 \mathrm{C}) \\
(0 \text { to } 35 \mathrm{C})\end{array}$} & $\begin{array}{l}1.05 \\
0.86\end{array}$ & $\begin{array}{l}0.23 \\
0.17\end{array}$ & $\begin{array}{l}0.30 \\
0.27\end{array}$ & $\begin{array}{l}2.69 \\
0.99\end{array}$ \\
\hline
\end{tabular}
(a) Smithsonian Meteorolorical Tables.
(b) Linear formula [Eq. (4)].
(c) Quadratic formula [Eq. (5)].
(d) Berry el al., $1945[\mathrm{Eq}$. (2)].
(e) Langlois, 1967 [Eq. (3)].
(f) Percent error $=100\left[\frac{\text { calculated value-accepted value }}{\text { accepted value }} \cdot\right.$.
(g) Mean percentage error $=\left[\frac{\left(\sum \text { percent error }\right)^{2}}{n}\right]^{\prime}$.

ones. Even the very simple linear formula (4) yields values that are closer to the accepted ones than does the formula of Langlois.

In the commonly occurring temperature range $0-35 \mathrm{C}$, the quadratic formula yields saturation values with a mean percentage error of 0.17 while that of Berry et al. (1945) yields values with a mean error of 0.27 . The linear formula provides values that have mean error of 0.86 while that of Langlois gives values with mean error of 0.99 .

The simple quadratic formula, therefore, yields saturation vapor pressure values that are within $0.2 \%$ of those given in the accepted tables and for large-scale computations its application is suggested.

\section{REFERENCES}

Berry, F. A. Jr., E. Bollay and N. R. Beers, 1945. IIandbook of Meteorology. New York, McGraw-Hill, 343 pp.

Groff, J. A., 1949: Final Report of the Working Subcommittee of the International Joint Committee on Psychrometric Data. Trans. ASME, 71, 903-913.

--, and S. Gratch, 1946: Low-pressure properties of water from -160 to $212^{\circ} \mathrm{F}$. Trans. Amer. Soc. Meating Ventilating lingrs, 52, 95-122.

Kiefer, Paul J., 1941. The thermodynamic properties of water and water vapor. Mon. Wea. Rev., 69, 329-331.

Langlois, W. E., 1967: A rational approximation for saturation vapor pressure over the temperature range of sea water. J. Appl. Meteor., 6, 451 .

List, Robert J., 1949: Smithsonian Meleorological Tables, 6th rev. ed., 5th reprint (1971). Smithsonian Institution Press, Washington D. C., 572 pp. 